\title{
O jornalismo como história imediata
}

\author{
ROBERTO ANDERSON DORNELLES \\ Universidade Federal do Rio de Janeiro (UFRJ) - E-mail: radornell@gmail.com \\ Virginia Pradelina da Silveira Fonseca \\ Universidade Federal do Rio Grande do Sul (UFRGS) - E-mail: virginia@ufrgs.br
}

\begin{abstract}
Resumo
O artigo trata da relação entre jornalismo e história. Toma-se a possibilidade de produção de conhecimento por parte do jornalismo e a teoria do acontecimento para refletir sobre o jornalismo como uma forma de registro da história imediata. Para isso, primeiramente argumenta-se em favor da hipótese de que a atividade jornalística é produtora de uma forma de conhecimento alicerçada na categoria de singularidade. A seguir, analisam-se os conceitos de acontecimento e acontecimento jornalístico para, por fim, tomar-se o conceito de história imediata para estabelecer a relação dessa forma de produção de conhecimento histórico com o jornalismo.
\end{abstract}

Palavras-chave

Jornalismo, história imediata, acontecimento

\begin{abstract}
This article analyses the connection between journalism and history. It considers the possibility of producing knowledge from journalism and also the event theory as a way to record history in an immediate way. To start with, it advocates the idea that journalism, as an activity, does produce knowledge, and that it is based on the singularity category. Next, the article analyses the concepts of event and of journalistic event. Eventually it studies the idea of immediate history to set up this relation between historical knowledge production and journalism.
\end{abstract}

\section{Keywords}

Journalism, immediate history, event

Artigo recebido em 19/05/2013

Aprovado em 23/06/2013 
$\mathrm{P}$ ara abordar a relação entre jornalismo e história, acredita-se necessária uma breve discussão sobre a possibilidade de o jornalismo, por meio da singularidade imanente à sua práxis, constituir-se forma de conhecimento. Esse é um ponto inicial de debate sobre a relação do jornalismo com o acontecimento e com a história imediata.

Um dos autores que primeiro abordaram a possibilidade de o jornalismo constituir uma forma de conhecimento foi Robert Park (2008), no ensaio "A notícia como forma de conhecimento: um capítulo dentro da sociologia do conhecimento"1. Neste, o autor utiliza as categorias "conhecimento de" e "conhecimento acerca de" formuladas originalmente por William $\mathrm{James}^{3}$, para distinguir as formas de conhecimento. Park define a primeira da seguinte maneira:

Acquaintance with [conhecimento de] é um tipo de conhecimento que alguém inevitavelmente adquire ao longo de seus encontros pessoais e de primeira mão com o mundo ao seu redor. É o conhecimento que vem do uso e costume mais do que qualquer tipo de investigação formal ou sistemática (PARK, 2008, p.52).

De acordo com o autor, o "conhecimento de" seria uma forma de conhecimento incorporada pelo hábito, pelo costume, resumindo-se em um conhecimento intuitivo e instintivo. Diferente desse, o "conhecimento acerca de" seria analítico e formal:

Em contraste, temos o tipo de conhecimento que James descreve como "conhecimento das coisas". Tal conhecimento é formal e sistemático. É baseado na observação e no fato, no fato que foi verificado, rotulado, regimentado e finalmente classificado dentro desta ou daquela perspectiva, de acordo com o objetivo e o ponto de vista do investigador. "Knowledge about" [conhecimento acerca de] é conhecimento formal; significa conhecimento que alcançou algum grau de exatidão e precisão pela substituição de ideias pela realidade concreta, e de palavras por coisas (PARK, 2008, p.55).

O sociólogo sustenta que essa segunda forma de conhecimento, que chama de "conhecimento científico" ou "conhecimento das coisas", não se constitui apenas em

\footnotetext{
${ }^{1}$ Ensaio publicado originalmente em 1940 no Americam Journal of Sociology.

${ }^{2}$ No original, Acquaintance with e Knowledge about.

${ }^{3}$ Filósofo e psicólogo estadunidense ligado à corrente filosófica do pragmatismo.
} 
forma de experiência acumulada. Para ele, "knowledge about" é um conhecimento que resulta da investigação sistemática da natureza e é buscado metodicamente com o aparato formal e lógico disponibilizado pela pesquisa científica.

Quanto ao jornalismo constituir uma forma de conhecimento, Park observa que a notícia não pode ser considerada uma forma de conhecimento sistemática como a das ciências, pois trata de eventos e não de coisas. No entanto, diz que a notícia pode ter para o público a mesma função que tem a percepção para o indivíduo. Segundo ele, "na sua forma mais elementar, o conhecimento chega ao público não na forma de uma percepção, como ele chega ao indivíduo, mas na forma de uma comunicação" (PARK, 2008, p. 60). Com isso, destaca que, diferentemente de outros campos da ciência, como a história, a notícia centra-se no presente:

A notícia, como forma de conhecimento, primeiramente não está interessada no passado ou no futuro, mas no presente. Pode-se dizer que a notícia existe somente no presente. [...] A notícia continua notícia até chegar às pessoas as quais ela possui "interesse de notícia". Uma vez publicada e reconhecida sua importância, o que era notícia vira história (PARK, 2008, p.59).

Dessa forma, sustenta que:

[a notícia] desempenha as mesmas funções para o público que a percepção desempenha para o indivíduo; isto é, não apenas informa, mas orienta o público, dando a todos a notícia do que está acontecendo. Ela faz isso sem qualquer esforço do repórter para interpretar os eventos que relata, exceto à medida que os torna compreensíveis e interessantes (PARK, 2008, p.60).

Adelmo Genro Filho (1987) é um dos autores que no Brasil debate criticamente as posições de Robert Park. O autor brasileiro resume a proposição de Park em relação ao "conhecimento de" como aquele que, posicionado diante de um saber complexo e abstrato, não ultrapassaria o aspecto fenomênico, que emana do convívio familiar, da imediaticidade da experiência e do hábito que lhe corresponde. Já o "conhecimento acerca de" seria, na leitura de Genro Filho (1987), um conhecimento formal, que resultaria de uma abstração controlada e criteriosa, isto é, lógico e teórico. No entanto, adverte que: 
O "conhecimento de" - indicado por Park como ponto inicial do contínuo onde se localiza a notícia - não é um "gênero" de conhecimento que possa ser concebido a-historicamente, fora das relações concretas de dominação e alienação. [...] Trata-se daquela esfera da vida cotidiana na qual a "práxis utilitária" configura os fenômenos da vida social como se fossem dados naturais e eternos, o mundo da pseudoconcreticidade. Por isso, a divisão sugerida por James, e assumida por Park, é redutora, pois supõe uma espécie de "senso comum" isento de contradições internas, cuja função seria somente reproduzir e reforçar as relações sociais vigentes, integrar os indivíduos na sociedade (GENRO FILHO, 1987, p. 57-58).

$\mathrm{O}$ autor também contesta a ideia de que o jornalismo poderia corresponder para o público às "mesmas funções que realiza a percepção para o indivíduo":

Se é verdade que o gênero de conhecimento produzido pelo jornalismo corresponde, em certo sentido, às "mesmas funções que realiza a percepção para o indivíduo", essa comparação não pode ser levada às últimas consequências. $\mathrm{Na}$ percepção individual, a imediaticidade do real, o mundo enquanto fenômeno é o ponto de partida. No jornalismo, ao contrário, a imediaticidade é o ponto de chegada, o resultado de todo um processo técnico e racional que envolve uma reprodução simbólica. Os fenômenos são reconstruídos através das diversas linguagens possíveis ao jornalismo em cada veículo. Consequentemente, não podemos falar de uma correspondência de funções entre o jornalismo e a percepção individual, mas sim de uma "simulação" dessa correspondência (GENRO FILHO, 1987, p. 58-59).

Segundo ele, é a partir dessa "simulação" que surge propriamente o gênero de conhecimento. Não houvesse essa "simulação", enfatiza, a relação imediata dos indivíduos com os fenômenos do cotidiano seria uma relação de experiência individual sem intermediação técnica ou racional instituída sistematicamente, resultando, com isso, em um grau determinado de conhecimento, um nível de abstração elementar.

Outro ponto contestado por Genro Filho (1987) reside no fato de que as duas formas de conhecimento expostas por Park se limitam a um sentido vulgar de "reflexo" subjetivo de uma relação meramente operacional com o mundo, e essa forma de compreender torna-se ainda mais complicada quanto transposta para o jornalismo. 
A partir de elementos potencialmente explosivos que atravessam todas as dimensões da produção simbólica de uma práxis socialmente dilacerada é que surge, de um lado, o reconhecimento da ideologia espontânea das classes dominantes e, de outro, a possibilidade de expansão da ideologia revolucionária a partir daquela. Ao não compreender essa questão, Robert Park acaba definindo o conhecimento produzido pelo jornalismo como um mero reflexo empírico e necessariamente acrítico, cuja função é somente integrar os indivíduos no "status quo", situá-lo e adaptá-lo na organicidade social vigente. O jornalismo teria, assim, uma função estritamente "positiva" em relação à sociedade civil burguesa, tomada esta como referência universal. [...] Ele supõe que o jornalismo é uma forma de conhecimento que realiza socialmente as mesmas funções (GENRO FILHO, 1987, p. 59-60).

Ao contrário de Park, Genro Filho (1987) defende que, se tomarmos o conhecimento como a dimensão simbólica do processo global de apropriação coletiva da realidade, pode-se conceber o jornalismo como uma das modalidades partícipes desse processo e, igualmente, atravessado por contradições.

Marx já indicou de forma inequívoca que a atividade prático-crítica dos homens está no coração do próprio conhecimento e, por isso mesmo, não se pode estabelecer uma contraposição absoluta entre sujeito e objeto, entre a percepção e a coisa ou, se preferimos, entre a atividade social que produz o mundo humano e os conceitos que desvendam o universo (GENRO FILHO, 1987, p. 60).

Na mesma linha, Meditsch (1997) também concebe o jornalismo como uma das formas que compõem a totalidade dos processos de construção do conhecimento. E faz uma síntese de três abordagens que tratam da possibilidade de o jornalismo ser uma forma de conhecimento. Na primeira, representada pelo austríaco Karl Kraus, sobretudo, a ciência é tida como "o" método de conhecimento e, assim, estaria descartada qualquer possibilidade de o jornalismo ser um produtor de conhecimentos, pois não teria condições de produzir qualquer conhecimento válido e, mais do que disso, a atividade jornalística contribuiria apenas para a degradação do saber.

A segunda abordagem analisada por Meditsch (1997) é a representada por Robert Park, que se discutiu acima. De acordo com o autor, essa segunda forma situa o jornalismo como conhecimento, mas como uma ciência menor, que, no entanto, não 
seria de todo inútil. E a terceira abordagem, segundo Meditsch (1997), enfatiza não o que o jornalismo tem de semelhante em relação às outras formas de produção de conhecimento, mas o que ele tem de único e original.

Para esta terceira abordagem, o Jornalismo não revela mal nem revela menos a realidade do que a ciência: ele simplesmente revela diferente. $\mathrm{E}$ ao revelar diferente, pode mesmo revelar aspectos da realidade que os outros modos de conhecimento não são capazes de revelar. [...] $\mathrm{O}$ Jornalismo não apenas reproduz o conhecimento que ele próprio produz, reproduz também o conhecimento produzido por outras instituições sociais. A hipótese de que ocorra uma reprodução do conhecimento, mais complexa do que a sua simples transmissão, ajuda a entender melhor o papel do Jornalismo no processo de cognição social (MEDITSCH, 1997, p.3).

Ao descrever a forma de conhecimento produzida pelo jornalismo, Meditsch (1997) destaca que, enquanto método analítico e demonstrativo, o jornalismo é muito frágil, pois trabalha com noções pré-teóricas para representar a realidade. Por outro lado, fortalece-se na medida em que as mesmas noções pré-teóricas orientam o princípio de realidade de seu público. Dessa forma, avalia que o conhecimento produzido pelo jornalismo será sempre menos rigoroso que o de qualquer ciência formal, mas, em compensação, para o seu público será também menos artificial, deslocado ou até mesmo esotérico. Em outras palavras, para o público em geral, o conhecimento produzido pelo jornalismo tem a potencialidade de ser mais facilmente assimilado do que o conhecimento produzido por uma determinada ciência que, em muitos casos, fica restrito ao seu próprio campo de pesquisa. Traçando comparação entre o jornalismo e as ciências formais, assinala que:

A revelação da novidade é um dado estrutural da retórica do Jornalismo - a conclusão a que conduz a sua argumentação. A forma com que chega a esta novidade também é diferente daquela utilizada pela ciência. Enquanto a ciência, abstraindo um aspecto de diferentes fatos, procura estabelecer as leis que regem as relações entre eles, o Jornalismo, como modo de conhecimento, tem a sua força na revelação do fato mesmo, em sua singularidade, incluindo os aspectos forçosamente desprezados pelo modo de conhecimento das diversas ciências (MEDITSCH, 1997, p.8). 
Com isso, assegura que o jornalismo não pode ser considerado uma "ciência mal feita", pois não é uma ciência e nem pode aspirar a ser. Mas avalia que, como forma de conhecimento, tem a possibilidade de revelar aspectos da realidade que escapam às metodologias das ciências, embora seja incapaz de explicar por si mesmo a realidade que se propõe a revelar. Ao postular que o jornalismo produz e reproduz um conhecimento válido e útil para as sociedades e seus indivíduos, Meditsch enfatiza que esse conhecimento tem os seus próprios limites lógicos e apresenta também uma série de problemas estruturais.

Como toda outra forma de conhecimento, aquela que é produzida pelo Jornalismo será sempre condicionada histórica e culturalmente por seu contexto e subjetivamente por aqueles que participam desta produção. Estará também condicionada pela maneira particular como é produzida. [...] Um dos principais problemas do Jornalismo como modo de conhecimento é a falta de transparência destes condicionantes. A notícia é apresentada ao público como sendo a realidade e, mesmo que o público perceba que se trata apenas de uma versão da realidade, dificilmente terá acesso aos critérios de decisão que orientaram a equipe de jornalistas para construí-la, e muito menos ao que foi relegado e omitido por estes critérios, profissionais ou não (MEDITSCH, 1997, p. 9-10).

Ao sustentar que o jornalismo é uma forma de conhecimento, Meditsch (1997) aponta para a problemática relativa à forma como esse conhecimento é produzido. $\mathrm{Na}$ mesma linha do autor, e também na de Genro Filho (1987), defende-se que o jornalismo constitui uma forma de conhecimento social e historicamente condicionado. Genro Filho (1987) trata da construção social dos fatos jornalísticos afirmando que a notícia é a sua unidade básica, sendo os fatos o objeto das notícias, a sua menor unidade de significação. No entanto, assim como outras disciplinas científicas constroem os fatos com os quais trabalham, o jornalismo também constrói os seus, tendo uma maneira própria de percebê-los:

Sabemos que os fatos não existem previamente como tais. Existe um fluxo objetivo na realidade, de onde os fatos são recortados e 
construídos obedecendo a determinações ao mesmo tempo objetivas e subjetivas. Isso quer dizer que há certa margem de arbítrio da subjetividade e da ideologia, embora limitada objetivamente. A objetividade oferece uma multidão infinita de aspectos, nuances, dimensões e combinações possíveis para serem selecionadas. Além disso, a significação dos fenômenos é algo que, constantemente, vai se produzindo pela dialética dos objetos em si mesmos quanto da relação sujeito-objeto. O material do qual os fatos são constituídos é objetivo, pois existe independentemente do sujeito. $\mathrm{O}$ conceito de fato, porém, implica a percepção social dessa objetividade, ou seja, na significação dessa objetividade pelos sujeitos (GENRO FILHO, 1987, p.186-187).

Com isso, destaca que a pretensa "objetividade jornalística" carrega consigo uma ideologia, que é burguesa, tendo a função de contribuir para reproduzir e confirmar as relações capitalistas. Conforme Genro Filho, essa "objetividade" de fundo positivista implica negar a dialética do processo histórico que constrói os fatos, resultando em uma compreensão do mundo como um agregado de "fatos" prontos e acabados, cuja existência seria anterior a qualquer forma de percepção e autônoma em relação a qualquer ideologia ou concepção de mundo. Nessa lógica, afirma, caberia ao jornalista a simples função de recolher os fatos da realidade como se fossem "pedrinhas coloridas".

Em um processo dialético, é possível dizer que o jornalismo cria os fatos que o sustentam, mas ao mesmo tempo é criado por eles, pois não pode arbitrariamente negar a realidade objetiva. Dessa forma, seguindo o raciocínio de Meditsch (2010), pode-se sugerir que o jornalismo não constrói a realidade social, mas pode se constituir como uma forma de socialização dessa realidade. Recorrendo a Berger e Luckmann, o autor afirma que, no processo de construção social da realidade, o jornalismo pode ser incluído entre os atores que contribuem significativamente para essa construção, embora não possa ser compreendido como "o" ator, nem mesmo como o principal.

Aceitando-se a hipótese de que o jornalismo constitui - ao lado dos demais atores sociais - uma forma de conhecimento que contribui para a socialização dos seres humanos, pergunta-se: de que forma faz essa socialização? Acredita-se que, para 
Estudos em Jornalismo e Mídia - Vol. $10 \mathrm{~N}^{\circ} \mathrm{I}$ - Janeiro a Junho de 2013

constituir-se forma de conhecimento que contribui para a socialização dos seres humanos, o jornalismo se assenta na categoria do singular.

Quem traz essa reflexão para o jornalismo é Genro Filho (1987), ao afirmar que as categorias filosóficas de universal, particular e singular ${ }^{4}$ podem oferecer o axioma teórico para uma teoria do jornalismo.

Os conceitos ${ }^{5}$ de singular, particular e universal expressam dimensões reais da objetividade e, por isso, representam conexões lógicas fundamentais do pensamento, capazes de dar conta, igualmente, de modalidades históricas do conhecimento segundo mediações que estabelecem entre si e as suas formas predominantes de cristalização (GENRO FILHO, 1987, p.160).

Tomando o jornalismo como práxis, o autor postula que o singular é categoria central.

As informações que circulam entre os indivíduos na comunicação cotidiana apresentam, normalmente, uma cristalização que oscila entre atmosfera cultural de uma imediaticidade compartilhada, uma experiência vivida de modo mais ou menos direto. [...] Somente o aparecimento histórico do jornalismo implica uma modalidade de conhecimento social que, a partir de um movimento lógico oposto ao movimento que anima a ciência, constrói-se deliberada e conscientemente na direção do singular. Como ponto de cristalização que recolhe os movimentos, para si convergentes, da particularidade e da universalidade (GENRO FILHO, 1987, p.160).

Portanto, com base em Genro Filho (1987), pode-se dizer que o singular constitui a matéria-prima do jornalismo, sendo a forma na qual se materializam as informações e para onde convergem as determinações particulares e universais.

Assim, o critério jornalístico de uma informação está indissoluvelmente ligado à reprodução de um evento pelo ângulo da singularidade. Mas o conteúdo da informação vai estar associado (contraditoriamente) à particularidade e universalidade que nele se propõem, ou melhor, que são delineadas ou insinuadas pela subjetividade do jornalista. O singular, então, é a forma do jornalismo, a estrutura interna através da qual se cristaliza a significação trazida pelo particular e o universal que foram superados. O particular e o

\footnotetext{
${ }^{4}$ Desenvolvidas, sobretudo, ainda que de forma idealista, pelo filósofo alemão G. W. Hegel, e sistematizadas a partir de uma concepção materialista e histórica por Karl Marx.

${ }^{5}$ Apenas nesta parte do texto Genro Filho utiliza o termo "conceito" para designar o singular, o particular e o universal, que, do ponto de vista filosófico, são considerados categorias.
} 
universal são negados em sua preponderância ou autonomia e mantidos no horizonte do conteúdo (GENRO FILHO, 1987, p.163, grifos no original).

Para Genro Filho (1987), o jornalismo não tem a função e nem propriedade para produzir um tipo de conhecimento como o da ciência, que privilegia as categorias lógico-universais incorporando e, em última instância, dissolvendo a feição singular do mundo. No entanto, o fato de a centralidade do jornalismo se localizar no singular não quer dizer que este singular seja elaborado de forma arbitrária e, por consequência, projetado fundamentalmente pela subjetividade do autor-jornalista. $\mathrm{O}$ autor explica que o processo de significação produzido pelo jornalismo situa-se no encadeamento de duas variáveis muito importantes: a) as relações objetivas do evento, o grau de amplitude e radicalidade do acontecimento em relação a uma totalidade social considerada; b) as relações e significações que são constituídas no ato de sua produção e comunicação.

No entanto, ressalva que a singularidade - que do ponto de vista filosófico constitui o objetivo da abordagem jornalística - não pode ser confundida com a forma vulgarizada de "jornalismo "objetivo"”. Segundo ele, neste "jornalismo objetivo" a preocupação com a singularidade dos fatos ou com a especificidade não é tratada do ponto de vista teórico, mas no sentido comum, constituindo um amontoado de coisas ou eventos singulares.

O resultado é que a singularidade é reificada pela compreensão espontânea do jornalista, que acaba aceitando implicitamente a particularidade e a universalidade sugeridas pela imediaticidade e reproduzidas pela ideologia dominante. Assim, a busca da "especificidade" na atividade jornalística limita-se a uma receita técnica de fundo meramente empírico, uma regra operativa que os jornalistas devem seguir sem motivo, tornando-se presa fácil da ideologia burguesa e da fragmentação que ela proporciona. A realidade transforma-se num agregado de fenômenos destituídos de nexos históricos e dialéticos. A totalidade torna-se mera soma das partes; as relações sociais, uma relação arbitrária entre atitudes individuais. O mundo é concebido como algo essencialmente imutável e a sociedade burguesa como algo natural e eterno, cujas disfunções devem ser detectadas pela imprensa e corrigidas pelas autoridades (GENRO FILHO, 1987, pp.155-156). 
Portanto, se tomarmos a categoria do singular como interpretada por Genro Filho (1987), podemos afirmar que, se o jornalismo tomar a história como um processo de autoprodução ontológica do gênero humano e a política como a dinâmica dos conflitos em torno da qualificação da práxis social, poderá então manifestar o seu potencial desalienante e humanizador. Dessa forma, pode produzir um conhecimento que poderá potencializar uma forma de organização social que possibilite a emancipação humana.

O jornalismo como forma de conhecimento tem na singularidade o potencial de desvelamento das contradições e implicações da particularidade e da universalidade de um determinado fenômeno histórico. Ao mesmo tempo, tem a capacidade de naturalizar os acontecimentos, histórica e contraditoriamente constituídos, por meio do poder simbólico que exerce ${ }^{6}$.

\section{Jornalismo e acontecimento}

Os fatos a que se refere Genro Filho (1987) podem ser tomados como sinônimo de acontecimento, embora possa haver distinções entre um e outro conceito ${ }^{7}$. O acontecimento estudado pelo campo da história, conforme Peter Burke (1992), remete à polêmica levantada pela Escola dos Annales $^{8}$ contra a história positivista, que privilegiava os grandes eventos, tidos como centro da história. No século XX, principalmente na França, surgiu uma forte rejeição ao que foi pejorativamente

\footnotetext{
${ }^{6}$ Não se desenvolve aqui este tópico, que, no entanto, encontra-se devidamente problematizado na dissertação Acontecimento e história nas páginas da revista Veja, aprovada no PPGCOM/UFRGS em 2011.

${ }^{7}$ Não é nosso objetivo fazer aqui essa distinção, que pode ser encontrada em Sodré (2009), Mouillaud (1997), Charaudeau (2007), Rodrigues (1993) e Benetti e Fonseca (2010), entre outros.

${ }^{8} \mathrm{O}$ que se convencionou chamar de Escola dos Annales foi um movimento que se constituiu em torno do período acadêmico francês Annales d'histoire économique et sociale. Foi fundada por Lucien Febvre e

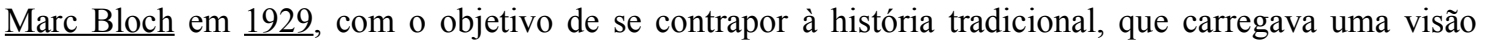
positivista, enfatizando a crônica de acontecimentos (histoire événementielle) e os grandes personagens. Os Annales substituíram o tempo breve da história dos acontecimentos pelos processos de longa duração e focalizaram a Análise das estruturas (BURKE, 1991).
} 
chamado de historie événementielle 9 . Os historiadores dos Annales, principalmente Lucien Frebvre e Fernand Braudel, passaram a privilegiar a história das estruturas nos seus estudos, pois compreendiam os acontecimentos como "a superfície do oceano da história, significativos apenas por aquilo que podiam revelar das correntes mais profundas" (BURKE, 1992, p.328).

Segundo Barbosa (2002), os estruturalistas procuravam demonstrar que a narrativa historiográfica desconsiderava muitos aspectos importantes do passado, sendo impossível conciliar a estrutura econômica e social com a experiência e modos de pensar das pessoas comuns. Nesse cenário, travou-se uma espécie de disputa entre aqueles que, como Braudel, defendiam que os historiadores deveriam considerar as estruturas mais seriamente do que os acontecimentos e outros que acreditavam que a função do historiador é apenas contar uma história (BURKE, 1992).

A partir de então, durante um longo período a historiografia permaneceu focada nas estruturas, prevalecendo sobre qualquer outro tipo de pesquisa que pretendesse tratar de temas como o cotidiano, ou como a história de um pequeno vilarejo. No entanto, embora tenha trazido ganhos para a prática historiográfica, esse tipo de abordagem também passou a ser fortemente contestada (BURKE, 1992).

O retorno à narrativa implicou a reabilitação do acontecimento como objeto, embora, como assinalou Pierre Nora (1977), "um outro tipo de acontecimento", que não o efêmero que remetia ao passado sem dar conta do presente. Esse novo acontecimento permitiria uma história propriamente contemporânea, pois diretamente ligada ao presente.

Neste sentido, o acontecimento pode ser compreendido como uma ocorrência que possui atualidade e ao mesmo tempo traz consigo um potencial de relevância e pregnância (REBELO, 2006).

Charaudeau (2007), por sua vez, observa que no mundo dos fenômenos existe, independentemente do olhar do homem, uma natureza que vive segundo princípios ${ }^{9}$ História dos Acontecimentos. 
energéticos que obedecem a leis que dependem de sistemas. Dessa forma, existiriam dois tipos de fenômenos que produzem, por consequência, dois tipos distintos de acontecimento. De um lado, fenômenos autogerados, que se desenvolvem segundo uma lógica interna, na qual os acontecimentos tornam-se previsíveis. Nestes casos, instaurase uma relativa estabilidade que se inclui na ordem dos estados de coisas (a sucessão das estações, a aparição de um ciclone). De outro lado, fenômenos heterogerados, que necessitam de incitações externas evenemenciais/acidentais para se desenvolverem, produzidos seja pelo encontro inesperado (coincidência, acaso) de elementos pertencentes a sistemas diferentes, seja pela aparição de um elemento externo ao sistema considerado, que funciona então como um acontecimento perturbador.

Dessa forma, defende que o acontecimento não é somente a “desordem”, mas que em um determinado momento pode caracterizar-se pela "ordem" (a necessidade), em outro momento pela "desordem" (o acaso, a contingência). Para Charaudeau, o acontecimento surge, desenvolve-se e extingue-se na dialética permanente da ordem e da desordem, dialética que pode estar na natureza, mas cuja percepção e significância dependem de um sujeito que interpreta o mundo. A forma como o acontecimento é visto e interpretado, de acordo com o autor, "depende do olhar que o sujeito humano lança sobre esse fato, ou seja, as redes que ele estabelece, através de sua própria experiência, entre diversos sistemas de pensamento e de crenças" (CHARAUDEAU, 2007, p.99).

Em sua definição de acontecimento, Quéré segue a linha de Charaudeau e Rebelo quando afirma que "o acontecimento apresenta, [...], um caráter inaugural, de tal forma que, ao produzir-se, ele não é apenas o início de um processo, mas marca também o fim de uma época e o começo de outra" (QUÉRÉ, 2005, p.60). Subsidiado por G.H. Mead, o autor avalia que o acontecimento nunca é inteiramente condicionado por aquilo que provocou ou tornou possível.

Ele [o acontecimento] introduz, necessariamente, alguma coisa de novo ou de inédito. Quando um acontecimento se produziu qualquer que tenha sido a sua importância, o mundo já não é o mesmo: as coisas mudaram. $\mathrm{O}$ acontecimento introduz uma descontinuidade só 
perceptível num fundo de continuidade. No entanto, apesar de a ocorrência de um acontecimento mudar qualquer coisa ao estado anterior do mundo, nem tudo o que acontece é descontínuo. Certos acontecimentos são esperados ou previstos, e quando se produzem são o resultado daquilo que os precedeu. A sua ocorrência faz, apesar disso, emergir algo de novo (QUÉRÉ, 2005, p.61).

No entanto, ressalta que, por mais descontínuo que seja, o acontecimento foi, em dada medida, condicionado. Condicionado, mas não determinado, enfatiza, pois as condições que levam ao seu surgimento são, de fato, necessárias, mas não o determinam completamente.

Louis Quéré destaca ainda que o acontecimento pode se constituir tanto em ponto final de determinado processo, como em ponto inaugural de outro. Segundo ele, quando um acontecimento se produz, primeiramente é tratado como um fato no mundo, situável no tempo e no espaço. Em seguida, busca-se identificá-lo através de uma descrição, procurando especificar as suas circunstâncias. Por fim, busca-se explicá-lo pela trama causal que o provocou, dando-lhe um sentido em função de um contexto prévio que o torne compreensível, socializar a surpresa que ele constitui atribuindo-lhe "valores de normalidade". Nessa perspectiva, o acontecimento torna-se um ponto final.

Em outra perspectiva, pode ser considerado um começo. Nesses casos, os acontecimentos deixam de ser apreendidos na sua origem como um passado ou uma trama causal, sendo que a sua significação já não é derivada de um contexto predefinido: constituem o seu próprio contexto de sentido.

Portanto, a especificidade do acontecimento estaria no fato de conseguir provocar efeitos no tempo e no espaço e projetar-se tanto para o passado como para o futuro.

Na seção a seguir, trata-se do acontecimento na perspectiva do jornalismo, considerando que este possa ser o elemento de mediação para a história imediata. 


\section{Acontecimento jornalístico}

Ao tratar das tipologias do acontecimento, Berger e Tavares (2010) acreditam existir pelo menos dois tipos de acontecimentos que se desdobram em muitos outros. $\mathrm{O}$ acontecimento vivido no cotidiano (acontecimento social) e o acontecimento jornalístico. O primeiro diz respeito à emergência e às afetações do acontecimento na realidade tangível e em suas consequências cognitivas. O segundo tem lugar nas reflexões dos estudos de jornalismo e diz respeito à construção do acontecimento em forma de notícia.

De acordo com os autores, é impossível separar rigorosamente a reflexão sobre os dois tipos de acontecimento. É por isso que se pretende evidenciar o papel do jornalismo no registro dos acontecimentos sociais. Para tanto, considera-se importante retomar as reflexões de Nora (1977), quando este avalia que a volta da narrativa e, por consequência de um "outro tipo de acontecimento", pressupõe que o presente seja o lugar temporal por excelência deste "outro tipo de acontecimento". Neste caso, o historiador francês diz que a história passaria a ser realizada por outros atores reunidos sob a assinatura dos mass media:

Era aos mass media que começava a pertencer o monopólio da história. A partir de agora, pertence-lhes. Nas nossas sociedades contemporâneas é através deles, e só através deles, que o acontecimento nos toca e não pode evitar-nos (NORA, 1977, p. 245).

Nora (1977) destaca que acontecimentos muito importantes podem vir a existir sem que deles se fale, fazendo com que o fato de que tenham existido não seja suficiente para torná-los históricos. Segundo o autor, para que realmente haja o "acontecimento" é preciso que ele seja conhecido e, é nesse ponto que a comunicação de massa demarca a sua importância, ao revelar e ao tornar conhecido um determinado acontecimento. Para ele, a relevância dos veículos de comunicação de massa pode ser compreendida pelo fato de que podem conferir a um discurso, a uma conferência, em síntese, a um determinado fato, algo que tem o caráter de irreversível. Portanto, sugere- 
nos que os veículos de comunicação de massa conferem a materialidade necessária para que o acontecimento possa estar definitivamente gravado na história, para que se torne um acontecimento histórico.

O autor reafirma essa ideia quando diz que, independentemente do acontecimento ser político ou social, literário ou científico, local ou nacional, o seu lugar estará sempre inscrito nas páginas dos jornais. Para Nora, portanto, o acontecimento descortinado pelos meios de comunicação de massa é a ruptura que põe em dúvida o equilíbrio sobre qual a organização social se sustenta.

Essa ideia parece ser compartilhada por Adriano Rodrigues (1993, p. 27) quando destaca que o acontecimento é "tudo o que irrompe na superfície lisa da história" e, mais do que isso, constitui no discurso jornalístico o referente do que se fala. É por isso que, segundo ele, uma das mais tradicionais regras da prática jornalística consiste em afirmar que a opinião deve ser livre, mas que os fatos são soberanos, pois são eles que dão a certeza da verdade.

Rodrigues (1993) distingue os fatos normais, que ocorrem por causas de fácil determinação, dos acontecimentos de natureza especial, que se tornarão acontecimentos jornalísticos. Estes, de acordo como o autor, irrompem sem nexo e nem causa aparente de fácil conhecimento, adquirindo com isso a característica de serem notáveis e, por consequência, dignos de registro na memória.

Charaudeau (2007) destaca que o acontecimento, para tornar-se, passa por uma operação de construção em que deverá ser selecionado e construído de acordo com o seu potencial de "atualidade", de "socialidade" e de "imprevisibilidade".

As perspectivas desses autores evidenciam que o acontecimento jornalístico tem categorias estruturantes, a notoriedade/excepcionalidade. Em outras palavras, a notoriedade dos acontecimentos sociais seria a base para a produção noticiosa, caracterizando-os, portanto, como acontecimentos jornalísticos.

Também Antunes (2008) problematiza a ideia de que o acontecimento deva ser 
Estudos em Jornalismo e Mídia - Vol. $10 \mathrm{~N}^{\circ} \mathrm{I}$ - Janeiro a Junho de 2013

constituído pela notoriedade/excepcionalidade. Ao se contrapor à concepção de que seria sempre percebido como uma ruptura, com o consequente surgimento de algo novo, o autor destaca que o acontecimento jornalístico pode trabalhar com uma concepção oposta a da ruptura.

Ocorre, assim, que o jornalismo também opera exatamente em direção oposta a essa ideia de ruptura, promovendo a integração do "novo" às categorias do já existente, como construído pelo sistema de informação e pela própria experiência social. Há, pois, uma figuração dos acontecimentos com base em uma estrutura arquetípica, há um padrão que retém alguns acontecimentos e despreza outros, os fatos visam os acontecimentos procurando de certa maneira estabilizá-los (ANTUNES, 2008, p.4).

Assim, o que o jornalismo faz é expor um acontecimento num processo que, recordando Charaudeau, Antunes chama de processo "evenemencial". Nesse ponto, a provável desordem causada pelo acontecimento e sua imprevisibilidade são contextualizadas, pelo jornalismo, em uma espécie de "mundo significado".

À percepção de algo que perturba uma ordem opõe-se, pelo relato jornalístico, um enredamento de causas, propósitos, motivos, agentes. $\mathrm{O}$ acontecimento funciona, pois, como uma ocorrência inicial que demanda a construção de uma interpretação, sua transformação em fatos, em acontecimentos jornalísticos (ANTUNES, 2008, p.4).

Com isso, o acontecimento jornalístico, ao contrário de ser caracterizado apenas pela ruptura, poderia ser considerado como a produção de um ponto rítmico na temporalidade cotidiana, como afirma Antunes (2008).

As perspectivas aqui expostas revelam o quanto pode ser complexa a discussão desses fenômenos. Considera-se importante, no entanto, pensar o acontecimento social diretamente ligado ao acontecimento jornalístico, pois não é possível dissociar os acontecimentos sociais dos acontecimentos jornalísticos. 


\section{Jornalismo como conhecimento histórico dos acontecimentos}

Nesta seção, apresenta-se o conceito de história imediata - conforme Lacouture (1998), Chauveau e Tétarart (1999) e Vicente (2009) - e debate-se a historicidade do jornalismo, asseverando-se a possibilidade de a história imediata ser a forma de historicidade do jornalismo.

De acordo com Lacouture (1998), a história imediata é uma forma de fazer história que não pode ser delimitada a um determinado enquadramento específico. Ela se caracteriza por ser construída num cenário em que há uma proximidade muito grande entre a redação da obra e o tema tratado, além de uma proximidade material do autor com aquilo que está sendo narrado ou estudado.

Observemos de saída que a imagem da "história imediata" tal como a percebemos não para de se mexer, recusando um verdadeiro enquadramento, bem como uma acomodação satisfatória. Do jornalismo bem pouco rigoroso, praticado por homens imersos no acontecimento a ponto de serem, ao mesmo tempo, participantes e reflexos dele, à pesquisa propriamente histórica que tem por objeto um período bastante recente e recorre aos métodos da enqueteentrevista. [...] Passa-se aquém e além de certa linha específica que seria a da história imediata, cujos componentes irredutíveis são, a um só tempo, proximidade temporal da redação da obra em relação ao tema tratado e proximidade material do autor em relação à crise estudada (LACOUTURE, 1998, p.216).

Portanto, as características principais desse tipo de história são: ser próxima, participante e ao mesmo tempo rápida na sua execução. Ela também deve ser produzida por um ator ou uma testemunha muito próxima do fato que está sendo analisado. Com isso, o autor salienta que os lugares privilegiados da realização da história imediata seriam os meios de comunicação de massa.

Se a imediação em tal domínio [o da história] é quase inacessível, isso vem do fato de que a operação histórica é verificação, delimitação, exclusão, coleção, e supõe a intervenção de um mínimo de meios técnicos de mediação, caneta, papel, cola, pastas, documentos. Não é por acaso que o veículo e o lugar privilegiado da "história imediata" assumiu a denominação global de meios de comunicação de massa (LACOUTURE, 1998, p. 216). 
Estudos em Jornalismo e Mídia - Vol. $10 \mathrm{~N}^{\circ} \mathrm{I}$ - Janeiro a Junho de 2013

É importante ressaltar que, neste artigo, não estamos tratando de história como conhecimento produzido pela ciência historiográfica, mas como registro de acontecimentos ainda em andamento. A principal contribuição da história imediata, a nosso ver, está no fato de possibilitar que os atores ou observadores muito próximos do acontecimento possam relatar a própria história.

Também é preciso lembrar que essa fórmula de "história imediata" não tende apenas a encurtar os prazos entre a vida das sociedades e sua primeira tentativa de interpretação, mas também dar a palavra aos que foram atores dessa história. Ela não apenas aspira à rapidez dos reflexos. Ela quer se elaborar a partir desses arquivos vivos que são os homens (LACOUTURE, 1998, p. 217).

O autor dá como exemplos emblemáticos dessa forma de história o clássico História da Revolução Russa, de Leon Trotsky, em que o autor foi um dos principais protagonistas do acontecimento, vivendo e contribuindo para a criação dos fatos, e História da Comuna, de Prosper Olivier Lissagaray, jornalista e militante socialista francês que participou ativamente do levante popular que ficou conhecido como Comuna de Paris, do qual tornou-se o principal historiador. Um terceiro exemplo seria o famoso Watergate, nos Estados Unidos. Segundo ele, o caso dos jornalistas do Washington Post, Bob Woodward e Carl Bernstein, autores da histórica reportagem "Os homens do presidente", que relatava minuciosamente o caso que culminou com a renúncia do presidente Richard Nixon, pode ser considerado como a produção de uma história imediata.

Duas outras características dessa forma de produção histórica, segundo Lacouture (1998), são: que os “imediatistas" trabalham em um estágio dos acontecimentos que os impede de saber a conclusão do que está em andamento; que os "imediatistas" tendem a trabalhar com os pontos altos dos acontecimentos e têm como base, em muitos casos, aquilo que é "sensacional".

No primeiro caso, o autor avalia que o historiador do imediato convive com a incapacidade de prever ou impossibilidade de saber o resultado do acontecimento que estuda. No entanto, essa "ignorância" poderia ser uma força ou uma virtude. No 
Estudos em Jornalismo e Mídia - Vol. $10 \mathrm{~N}^{\circ} \mathrm{I}$ - Janeiro a Junho de 2013

segundo, Lacouture (1998) destaca que a característica de o "imediatista" trabalhar com os "picos" se deve ao fato de que é no ponto alto dos acontecimentos que surgem as maiores "tempestades", ou seja, os pontos mais interessantes dos acontecimentos.

Por fim, o autor enfatiza que a história imediata é marcada por ser forma de produção de conhecimento histórico impulsionada pelos meios de comunicação.

A história imediata não é uma futilidade de nosso século [XX]. É uma secreção e uma projeção. O que caracteriza o mundo convulsionado e comunicante em que vivemos não é apenas o fato de que toda a crise nos deixa em palpos de aranha, seja ela provada pela criação de um "mochar" israelense em Golan, pelo desastre de automóvel de um Emir na costa dos Piratas ou por uma greve na Cracóvia, e de que essa crise pode, a qualquer momento, subverter nossa vida, deter o processo de produção ou condenar ao frio nações inteiras, mas sim que esses acontecimentos sejam logo levados a conhecimento da opinião pública afligindo-a, projetando-a na angústia. É essa imediação da comunicação que impõe o desenvolvimento da história imediata, sinais de bruma de uma sociedade alucinada por informações e no direito de exigir inteligibilidade histórica próxima (LACOUTURE, 1998, p.238).

Desse ponto de vista, os meios de comunicação podem ser caracterizados como locais onde se manifestam os cenários dos acontecimentos daquele instante, fazendo assim uma história imediata. É possível dizer, na linha de Chauveau e Tétarart (1999), que o jornalismo é o grande potencializador da história imediata:

De certa maneira, ela [a história imediata] é filha da imprensa. De fato, foram a pressão jornalística e a demanda social conjugadas que impuseram o princípio da história imediata a partir dos anos 1950. [...] O procedimento da história imediata é mais parecido com as técnicas jornalísticas do que com as da ciência histórica. Os fatores conjugados que lhe deram nascimento não resultam, em primeiro lugar, do princípio inicial da história: o recuo, o desprendimento com relação ao fato (CHAUVEAU e TÉTART, 1999, p.22).

É importante destacar, no entanto, que a capacidade de o jornalismo produzir um tipo de história não é consensual. Charaudeau (2007), por exemplo, acha que a característica das mídias é essencialmente a-histórica, e assim sustenta a a-historicidade da notícia, assegurando que a co-temporalidade do jornalismo não tem qualquer proximidade com a de outros domínios, sobretudo, da história. O argumento é que na 
Estudos em Jornalismo e Mídia - Vol. $10 \mathrm{~N}^{\circ} \mathrm{I}$ - Janeiro a Junho de 2013

produção do conhecimento histórico a contemporaneidade é mais extensa, inscreve-se no campo do perene, do tempo da longa duração.

Ao representar o mundo, a notícia, portanto, traria consigo uma superficialidade, uma efemeridade. $\mathrm{O}$ caráter de atualidade focado em responder a questão “o que se passa nesse momento?" não permitiria que a notícia tivesse uma perspectiva quanto ao passado, ou pudesse fazer uma projeção para o futuro.

Neste ponto, encontra a oposição de Antunes (2007), ao argumentar que distinguir a notícia da história não implica negar-lhe historicidade.

Como diz Tétu (2003), a interpretação da ação relatada na notícia supõe o acionamento de formas culturais "tomadas de empréstimo" à história. A questão seria pensar qual a relação da notícia com a historicidade. Se condenamos a notícia pela sua falta de duração, por se constituir em um evento que existe para substituir outro evento noticioso numa deriva sem fim, talvez fosse importante lembrar que o transitório e o descontínuo compõem toda duração histórica (ANTUNES, 2007, p.34).

$\mathrm{O}$ autor ressalta que a notícia não trata, de fato, de uma retrospectiva de acontecimentos históricos, mas "orienta sua co-temporalidade entre acontecimento e circulação do acontecimento, não os privando e sim os orientando por linhas de fuga que figuram representações de passado e futuro" (ANTUNES, 2007, p.35).

Considera-se importante a referência de Charaudeau (2007) em relação à dinâmica da atividade jornalística, calcada, sobretudo, na atualidade. Contudo, concorda-se com Antunes (2007) quanto à questão de que a atualidade do jornalismo não o afasta de uma produção de conhecimento histórico. Acredita-se, com base em Nora (1977), Lacouture (1998), Vicente (2009) e Chauveau e Tétarart (1999), que a duração histórica contida na notícia é o imediato e, é nesse sentido, que se defende a relação da história com o jornalismo e, mais do que isso, a historicidade da prática jornalística. 
Isso possibilita, na relação do campo da comunicação com o da história, asseverar a possibilidade de que o jornalismo, ao descrever uma determinada realidade, possa vir a realizar a produção de um conhecimento histórico e, sobretudo, a se tornar uma fonte privilegiada para pesquisadores produzirem conhecimento do ponto de vista da ciência historiográfica. Portanto, antes de ser antagônica ou completamente distinta, a produção jornalística pode ser considerada complementar à produção da ciência historiográfica.

\section{Considerações finais}

Cabe destacar, por fim, que a história imediata produzida pelo jornalismo é uma versão dos acontecimentos sociais ocorridos em determinado período e contexto histórico. Além disso, é um ponto de vista de determinada publicação sobre um acontecimento muitas vezes em desenvolvimento. Em síntese, a história imediata surge da apropriação do acontecimento social pelo jornalismo, que o registra como acontecimento jornalístico, e não de uma pesquisa profunda e elaborada metodologicamente, que caberia ao campo da ciência historiográfica realizar. Ao fim e ao cabo, contudo, tanto a História quanto o Jornalismo estarão produzindo conhecimento a partir de suas distintas formas de se apropriar do acontecimento. 


\section{Referências Bibliográficas}

ANTUNES, Elton. Temporalidade e produção do Acontecimento jornalístico. Revista Em Questão, Porto Alegre, v. 13, n. 1, p. 25-40, jan/jun 2007.

ANTUNES, Elton. Acontecimento, temporalidade e a construção do sentido de atualidade no discurso jornalístico. Revista Contemporânea. Vol. 6. nº 1. Jun. 2008.

BARBOSA, Marialva. O acontecimento contemporâneo e a questão da ruptura. In: Semiosfera - Revista de Comunicação e Cultura. Rio de Janeiro, volume 2, número 1, maio de 2002. Disponível em: < http://www.semiosfera.eco.ufrj.br/anteriores/semiosfera02/organizacao/txtsoc1.htm $>$ Acesso em 29. Mai.2011.

BURKE, Peter. A história dos acontecimentos e o renascimento da narrativa. In: BURKE, Peter (Org.). A escrita da História: novas perspectivas. São Paulo: Unesp, 1992.

BURKE, Peter. A Revolução Francesa da Historiografia: a Escola dos Annales 1929-1989. São Paulo: Editora da Unesp, 1991.

BENETTI, Marcia; FONSECA, Virginia Pradelina da Silveira Fonseca. Jornalismo e Acontecimento: mapeamentos críticos. Florianópolis: Insular, 2010.

BERGER, Christa; TAVARES, Frederico. Tipologias do acontecimento jornalístico. In: BENETTI, Marcia; FONSECA, Virginia P. S. (orgs.). Jornalismo e Acontecimento: mapeamentos críticos. Florianópolis: Insular, 2010, pp.121-142.

CHARAUDEAU, Patrick. Discurso das Mídias. São Paulo: Contexto, 2007.

CHAUVEAU, Agnès; TÉTART, Philippe. Questões para a história do presente. In: CHAUVEAU, Agnès; TÉTART, Philippe (Org.). Questões para a história do presente. Bauru/SP: EDUSC, 1999.

DORNELLES, Roberto Anderson. Acontecimento e história nas páginas da revista Veja: uma análise das reportagens sobre o primeiro governo da ditadura civil-militar argentina (1976-1981). 2011. Dissertação - Programa de Pós-Graduação em Comunicação e Informação, Faculdade de Biblioteconomia e Comunicação, Universidade Federal do Rio Grande do Sul, Porto Alegre.

FONSECA, Virginia Pradelina da Silveira. O acontecimento como notícia: do conceito à prática profissional. In: BENETTI, Macia; FONSECA, Virginia Pradelina da Silveira Fonseca. Jornalismo e Acontecimento: mapeamentos críticos. Florianópolis: Insular, 2010 (pp. 167-185).

GENRO FILHO, Adelmo. O segrego da pirâmide: para uma Teoria Marxista do Jornalismo. Porto Alegre: Editora Tchê, 1987.

LACOUTURE, Jean. A História Imediata. In: LE GOFF, Jacques; CHARTIER, Roger; REVEL, Jacques. A História Nova. 4. ed. São Paulo: Martins Fontes, 1998, pp.215-240.

MEDITSCH, Eduardo. O jornalismo como forma de conhecimento? Conferência proferida nos cursos de verão da Arrábida, Portugal, setembro de 1997. Disponível em < http://www.bocc.ubi.pt/pag/meditscheduardo-jornalismo-conhecimento.pdf. Acesso em 23/12/2011 > Acesso em 21/09/2010.

MEDITSCH, Eduardo. Jornalismo e construção social do acontecimento. In: BENETTI, Marcia; FONSECA, Virginia P. S. (orgs.). Jornalismo e Acontecimento: mapeamentos críticos. Florianópolis: Insular, 2010, p.19-42.

MOUILLAUD, Maurice. A crítica do acontecimento ou o fato em questão. In: PORTO, Sergio Dayrell (Org.). O jornal: da forma ao sentido. Brasília: Paralelo 15, 1997. 
Estudos em Jornalismo e Mídia - Vol. $10 \mathrm{~N}^{\circ} \mathrm{I}$ - Janeiro a Junho de 2013

NORA, Pierre. O regresso do acontecimento. In: LE GOFF, Jacques. Fazer História 1: novos problemas. São Paulo: Bertrand, 1977.

PARK, Robert. A notícia como forma de conhecimento: um capítulo dentro da sociologia do conhecimento. In: BERGER, Christa; MAROCCO, Beatriz (orgs.). A era glacial da imprensa. Porto Alegre: Sulina, 2008. Volume 2.

QUERÉ, Louis. Entre facto e sentido: a dualidade do acontecimento. In: Trajectos - Revista de Comunicação, Cultura e Educação. Lisboa, nº 6, 2005, p. 59-76.

REBELO, José. Apresentação. In: Trajectos - Revista de Comunicação, Cultura e Educação. Lisboa, $\mathrm{n}^{\circ}$ 6, 2005.

RODRIGUES, Adriano Duarte. O acontecimento. In: TRAQUINA, Nelson (Org.). Jornalismo: questões, teorias e "estórias". Lisboa: Veja. 1993.

SODRÉ, Muniz. A narração do fato: notas para uma teoria do acontecimento, Petrópolis: Vozes, 2009.

VICENTE, Maximiliano Martin. História e comunicação na ordem internacional. São Paulo: Editora UNESP; Cultura Acadêmica, 2009.

Estudos em Jornalismo e Mídia está sob a Licença Creative Commons

Este artigo e todo o conteúdo da Estudos em Jornalismo e Mídia estão disponíveis em http://www.periodicos.ufsc.br/index.php/jornalismo/index 